\title{
Exploring of Self-management Experience among Health Professional Survivors from Coronavirus Disease 2019 in West Nusa Tenggara, Indonesia
}

\author{
Satriya Pranata ${ }^{1,2} \mathbb{D}$, Shu-Fang Vivienne $\mathrm{Wu}^{1 *}(\mathbb{D})$, Hendri Purwadi ${ }^{3,4}$, Dewa Gede Sanjaya Putra ${ }^{3,4}$, Herlinda Wulandari ${ }^{2}$, \\ Edy Soesanto ${ }^{2}$ \\ ${ }^{1}$ Department of Nursing, School of Nursing, National Taipei University of Nursing and Health Sciences, Taipei, Taiwan; \\ ${ }^{2}$ Department of Nursing, Faculty of Nursing and Health Sciences, Universitas Muhammadiyah Semarang, Semarang, Central \\ Java, Indonesia; ${ }^{3}$ COVID-19 Isolation Room, Manambai Abdulkadir General Hospital, West Nusa Tenggara, Indonesia; \\ ${ }^{4}$ Department of Nursing, Institute of Health Science Griya Husada, Sumbawa, West Nusa Tenggara, Indonesia
}

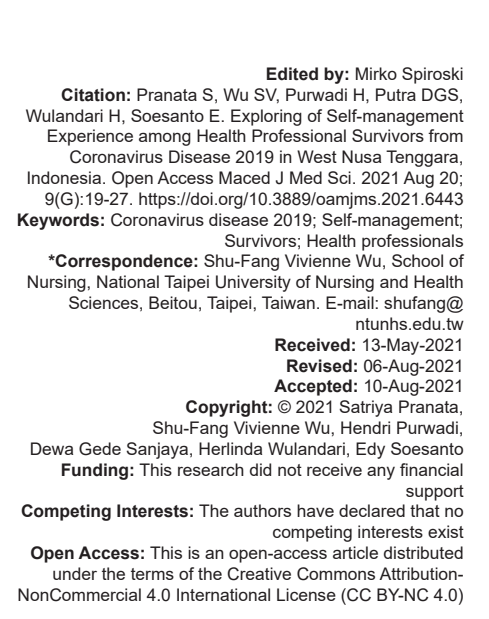

Abstract

BACKGROUND: Coronavirus is a health problem that is happened worldwide and impacted on many sectors. However, there is no research that provides information on health professional survivors from coronavirus disease 2019 (COVID-19) experience in self-management.

AIM: The purpose of this study is to explore self-management experience among health professional survivors from COVID-19 in West Nusa Tenggara, Indonesia.

METHODS: Purposive sampling, one-on-one, in-depth with semi-structural interviews was conducted to collect the data in this study. Data saturation was achieved after interviewing twelve health professional survivors from COVID19 in West Nusa Tenggara, Indonesia. Narratives were analyzed by Colaizzi's (1978) seven-step method.

RESULTS: Four emergent themes were identified in this study including self-awareness (preventing transmission, improving immunity system, dietary adjustment and accessing appropriate treatment), social relationship (negative feeling and social support), stress management (sharing experience each other's, reducing negative emotional, and self-introspection), focus on learning (looking for information from survival COVID-19, looking for information from YouTube and looking for information from google search).

CONCLUSION: The experience among health professionals in self-management while struggling to recover quickly from COVID-19 can be used as valuable information for Indonesian society.

\section{Background}

In the beginning of 2020 , the coronavirus became a worldwide pandemic [1]. It was known that the origin of this virus originated from Wuhan, China, in December 2019. It has been confirmed that the country which affected by coronavirus has reached 219 countries [2]. More than 188 million people in the world were infected by coronavirus disease 2019 (COVID-19) and more than 2 million died [2]. Data those reported in Indonesia at February 2021 where totaled of people with COVID-19 were more than 36 thousand died and more than 1.1 million recovered [3].

Other data show that the number of deaths among health professionals in Indonesia included into top three in the world and number one in Asia [3], [4]. Since March 2020 or when the first case of COVID-19 appeared in Indonesia until January 2021, there were 647 health professionals died due to being infected with the coronavirus. The number consists of 289 doctors and
27 dentists, 221 nurses, 84 midwives, 11 pharmacists, and 15 medical laboratory personnel. Moreover, the province of West Nusa Tenggara is included in the provision category with the highest number of health professional infected with COVID-19 in Indonesia [3].

In reality, most of the health workers who are infected with COVID-19 in West Nusa Tenggara are not treated at the hospital, but only enough to do self-management and self-isolation at home [5]. This decision was taken because majority of them without severe signs and symptoms. Another consideration of self-isolation at home was the health workers had sufficient knowledge as well as ability to perform their self-management at home. Moreover, the hospitals were full of COVID-19 patients from civil society who had severe signs and symptoms [6], [7].

Previous studies on COVID-19 in Indonesia mainly focused on epidemiological, clinical, and radiological features of patients with confirmed infection [3], [8], [9]. However, there is no research that provides information on health professional survivors 
from COVID-19 experience in self-management, especially in West Nusa Tenggara, Indonesia. Exploring of experience among health professional survivors from COVID-19 regarding self-management is necessary because it can help government determine the most appropriate rules and regulations regarding the needs of health professionals during self-isolation at home. This is important because health workers are the final guard which determine the quality of health services in the hospitals.

\section{Purpose}

The purpose of this study is to explore selfmanagement experience among health professional survivors from COVID-19 in West Nusa Tenggara, Indonesia.

\section{Methods}

\section{Study design}

Qualitative research explores unknown areas of knowledge. Phenomenology explores the meaning of a live experience from the individual's perspective. Qualitative researchers usually take a person-centered and holistic perspectives; phenomenology is a qualitative approach designed to seek people's life world and lived experiences to gain insight and extract the essence of the experience that human beings have in common beyond personal cases. The cases objectively described the phenomena and obtained the truth of matters in the broadest sense [10]. Husserl defined phenomenology as "the science of essence of consciousness" and promoted the meaning of lived experience as a rigorous way of understanding the world [10]. Colaizzi (1978) developed a method of phenomenological analysis based on Husserl's descriptive phenomenology [11]. From this philosophical stance, the meaning of an experience is described within emergent themes and common patterns from specific experiences [11], [12], [13].

As the focus this study was to understand of selfmanagement experience among health professional survivors from COVID-19 in West Nusa Tenggara, Indonesia, Colaizzi's (1978) phenomenological approach was used because it provides a clear structure for analyzing data [11].

\section{Settings and participants}

The researcher recruited the participant using a purposive sampling method. A total of 12 respondents were participated. Before conducted the interview, the participant who intended to participate had gotten explanation about the study aims and procedures.
Several of eligibility criteria were set for selecting the participant, such as: Health professionals from West Nusa Tenggara who recovered from COVID-19 for at least 2 week, willing to participate in the research, had signed the informed consent form, willing to express their feelings, thoughts and share their experiences through an in-depth interview.

\section{Data collection}

Following consent, participants were asked by the researcher to describe their experiences related to self-management, using a semi-structured interview guide with several broad questions, such as:

1. Would you tell me how long have you been infected of COVID-19?

2. What kinds of experience changed after infected of COVID-19?

3. How do you deal with all the changed experience after infected from COVID-19?

4. Would you express all the feelings and thoughts after infected from COVID-19?

5. What difficulties do you experience after infected from COVID-19?

6. Do you have expectations during infected and after recovered from COVID-19?

7. Do you have more information to be shared regarding your experience to handle your condition after infected from COVID-19?

Probing questions were also prepared to encourage the participants to give more information about their experiences, such as "Can you tell me more about that?." At the end of interview, the question "Is there anything else you would like to tell me?" was a positive closure to interviews (Polit and Beck, 2015). Interviews were conducted by face to face according to the patient's will. Interviews lasted 15-30 min and were digitally recorded and transcribed verbatim.

\section{Data analysis}

The interview results were analyzed by the researcher according to Colaizzi's phenomenological analytic method (Colaizzi, 1978). It consists of seven steps, (Polit and Beck, 2015) such as:

1. Read all protocols to acquire a feeling for them

2. Review each protocol and extract significant statements

3. Spell out the meaning of each significant statement

4. Organize the formulated meanings into clusters of themes

5. Integrate results into an exhaustive description of the phenomenon under study

6. Formulate an exhaustive description of the phenomenon under study in as unequivocal a statement of identification as possible 
7. Ask participants about the findings thus far as a final validating step.

The first step was to acquire a sense of each transcript. In this study, each interview was listened to and checked for audibility and integrity as soon as possible when the interview was completed. The interview was transcribed verbatim and returned so that the participants ensured that meaning was preserved. The interview transcript was written in Indonesian and translated into English by researcher. Each transcript was read several times until a sense of patient's experience of self-management during self-isolation was clear. All thoughts, feelings, and ideas were written during this stage.

The second step was to extract significant statements. Statements and phrases about the experience of self-management at home were extracted from each transcript. These were debriefed and discussed with the research team.

The third step was to formulate the meaning of each significant statement. The extracted statements related to self-management among health professional survivors from COVID-19 in West Nusa Tenggara were interpreted into underlying meanings derived from the significant statements. The fourth step was to organize the formulated meanings into clusters of themes, each cluster of which was coded, including all grouped formulated meanings.

The fifth step was to integrate the results with an exhaustive description containing all the dimensions related to self-management among health professional survivors from COVID-19 in West Nusa Tenggara, Indonesia. The sixth step was to describe the fundamental structure of the phenomena. At this stage, redundant descriptions were eliminated to establish the fundamental structure and generate specific relationships between the clusters of themes and extracted themes. Transcripts were re-analyzed to confirm that themes represented the experiences of the participants to ensure consistency of the data analysis.

The seventh step was to return these research findings to the participants for discussion. All participants gave feedback that the results reflected the meaning of their experiences regarding self-management among health professional survivors from COVID-19 in West Nusa Tenggara, Indonesia.

\section{Trustworthiness}

Credibility, transferability, dependability, and confirmability were enhanced by using Shenton's framework [15]. Questions were asked in a logical sequence in semistructured interviews; after each interview, the participant was given a copy of their transcript to affirm the accuracy of the data, and they could give any additional information after the interviews. The researcher attempted to remain as neutral as possible, be aware of presuppositions about how the self-management among health professional survivors from COVID-19 in West Nusa Tenggara, Indonesia is. The research team discussed the findings during the analysis process to make sure that themes that emerged from narratives of participants' descriptions reflected their experiences. The provision of verbatim quotations provided a check to ensure that the researchers faithfully presented the participants' experience.

\section{Ethical approval}

Participants provided written informed consent procedures to participate in this study. This study also was successfully accepted by the hospital and local government.

\section{Results}

Four emergent themes were identified to illustrate the self-management experiences among health professional survivors from COVID-19 in West Nusa Tenggara, Indonesia. These themes were (1) Self-awareness, (2) Social relationship, (3) Stress management, and (4) Focus on learning.

\section{Self-awareness}

Understand and reflect on various COVID-19 situations through foreign exchange strategies to prevent COVID-19 transmission in the surrounding environment and their families with various efforts such as disinfecting the area around where they live, increasing personal immunity through dietary adjustment, and increasing vitamin consumption. This is done on the basis of personal self-awareness without coercion from any party. This theme included four subthemes: preventing transmission, improving immunity system, dietary adjustment, and accessing appropriate treatment.

\section{Preventing transmission}

The effort that I am doing after recovering from COVID-19 is practicing a good hand hygiene, maintaining a physical distancing and staying at home. After recovering form COVID-19, I maintained personal hygiene which is something that I did not pay attention before. In the past, I often hanged out with my friends and often forget to practicing hand hygiene, but now, I am practicing hand hygiene more often as well as maintaining a physical distancing (participant 1).

I have a separated bathroom and good ventilation at home, that's way I did self-quarantine at home (participant 2). 
Now I strictly keep my body healthy because I afraid of being re-infected. I try to more careful and cautious. I use hand-sanitizer more frequently, I keep my environment clean by moping it with mixing bycline (moping substance) and water. I also spray the surrounding with hand-sanitizer. Every time I am coming home, I have to take a shower and doing oral hygiene using betadine (participant 2).

I fully had no contact with my children when I was getting infected because I put their health as the most priority rather than anything. To overcome that situation, now I am avoiding crowds and public gathering. I used my own bathroom whereas my husband used the another one (participant 3 ).

I used to be the usual one (not following health protocol), but now, I try to be more conservative, prefer to more closely (stay at home). Hence, if there is no important thing, I try to not sitting down in the room (office room) and going home on time (participant 4).

Usually, when I wake up, I do sun bathing as well as drying pillows and bed cover. I have separated my bedroom with my husband. I also eat separately even though still in the same room. I try to live healthy by wearing a mask everywhere (participant 5 ).

I wear a mask more often even though at home (participant 6).

The health protocol 3M (Indonesian terms) have to be followed (Participant 7 ).

I have practiced the healthy live behavior even before getting infected of COVID-19. Now I am practicing $5 \mathrm{M}$ (health protocol Indonesian term); hand hygiene wearing a mask need to be a more priority (participant 8).

I am doing healthy live behaviors such as taking a bath (regularly) in the morning and evening, because before getting infected, I took a bath once a day. Now I am wearing mask regularly, practicing hand hygiene more often (Participant 9).

What I have done (when self-quarantine) was disinfecting (surrounding), took sunbathing and doing gymnastics. I think before getting COVID-19, I did not wear mask properly but now, I get used to wear mask at home as well as practicing hand hygiene. Just that's it, and now I try to reduce going shopping bro (Participant 10).

The very first thing that I have done (when getting infected) was doing personal hygiene, especially in my bedroom. I tried to change the bed linen every day. I sprayed bedroom and the environment which I hold often. Every time I eat something, I brush my teeth to maintain oral hygiene (Participant 11).

During a self-quarantine, I wear a mask and reduce contact to everyone as well as cleaned up all frequently used stuffs. My habit is changed, I open my house ventilation every morning and evening, moping 2 times a day even though I have finished a self-quarantine. I try hard to keep physical distancing with my family and the community until now (Participant 12).

\section{Improving immunity system}

I try to do sunbathing every day at 9 am (Participant 1).

I keep my sleep pattern to more routine and regular (Participant 2).

Taking a rest at home more frequently (participant 7).

Now, I sleep more soundly which was $6 \mathrm{~h}$ to $8 \mathrm{~h}$ a (a day). Now, I take a rest more structured as well as my diet and activities. During COVID-19, I exercised regularly (Participant 8 ).

Before getting infected, I stay up late because of drinking a coffee, but now I reduce to drink coffee so I my bedtime is sooner (participant 9 ).

Until now, I am still doing sunbathing (Participant 11).

Now, we boost immune system through healthy dietary pattern (participant 12).

\section{Dietary adjustment}

The effort that I made after recovering from COVID-19 was taking vitamins form the hospital and eating foods which contain lots of Vitamin $C$ and $D$ as well as vegetables (participant 1).

After recovering from COVID-19, I just keep eating when I get hungry (participant 2).

Usually, I have a food choice, but during self-quarantine, I always eat whenever I get chance (participant 3).

I have to eat regularly (participant 5 ).

Choosing the right foods and consume more food than usual (Participant 7).

In the past I ate junk food but now I prefer vegetable, lots of protein such as tofu and tempe (Indonesian food) (participant 8).

Now, I routine to eat a healthy food (Participant 11).

\section{Accessing appropriate treatment}

I have to take Vitamins, both herbs and medicines everyday (Participant 2).

I focus on taking vitamins, eating healthy food and taking a rest regularly. In addition, I do sunbathe every day (Participant 3 ).

I have to take vitamin regularly (Participant 5). 
(When being infected) I took a medicine such as Vitamin C every day, sometimes I took Imbost Force 1 (herb vitamin) a once a week. In addition, I did regular exercise and sunbathing, something that I never done before (participant 6).

It is important to take vitamin regularly (Participant 7).

Before getting infected, I never took vitamins, but now I take vitamin and milk almost every day (Participant 8)

I usually take redoxon (vitamin) in the morning and the coconut water in the noon (Participant 9).

I took herb such as Extract ginger, honey, coconut water (effective). That's why I tried. (Participant 9).

I take vitamin regularly (Participant 11).

Now, I take vitamin more often and regular (Participant 12).

\section{Social relationship}

COVID-19 has changed the social relationships of sufferers. This condition triggers them to think about negative things. With the COVID-19 they suffered, they had various obstacles in making social relationships, especially with their closest people or family. Disturbed negative feelings and social support also indirectly impact on the self-management they undergo during infection. Themes of social relationship in this study divided into two sub-themes, namely negative feeling and social support.

\section{Negative feeling}

I feel bad when being seen by other people. It is not like usual when I can gather with my friends, and now I tend to avoid a gathering (Participant 1).

When I being infected, I had a physiological problem that I think was usual, overthinking. I think other people did not experience (such feeling) but it was obvious for me. I felt overwhelming. I thought the negative thing (may happened to me). Moreover, when I read the news about the negative effect of Covid-19, I felt breathless. I did not turn off the light, I let the window open, I did such activities to anticipate if something bad happened to me, therefore, other people (family) could help me immediately. I often warn my family (about the people who were suspect of COVID-19), I said that suspecting other people of COVID-19 is common because we don't know who they were talking with (Participant 2).

I was worried because I still had a little cough, and it was persistent. I was thinking what if I used the supplementary of oxygen to overcome my breathless. I thought and was afraid to get re-infected because some of my friends who had recovered got re-infected.
I used to think about how other people was thinking about me and my family. I was worried that other people stay away from me. I still have bad feeling when meet other people. I was worried what if they got infected because of me. I would be accused as spreader of COVID-19. I also worried about my children, who will take care of him and feeding him (if I get re-infected) (Participant 3).

I still worry and feel annoyed that other people feel uncomfortable with me. Yes, I still have sense of not being calm, feeling insecure meeting with my office mate. It's burden for being confirmed person of COVID-19 because being recovered is not easy, because people might think we still carry that virus in my nose (participant 4).

I felt that people avoid me. I am worried that other people might think they get infected because of me or carrier of COVID-19 in the community (participant 5).

I still worry even thought I have recovered (negative) from COVID-19. I worried that I could transmit (COVID-19) again (to other people). When the first time I knew that I was being infected, oh my god, I thought that it would be the end of my life. When I admitted to isolation room (in the hospital), I felt the pressure. Oh god, I felt it was really sick and nothing I could do. (because) cell of our body could not work (normally). I still afraid to take off the mask and to make contact for too long (with other people, even though I've already negative. I felt worried to involve in social activities such as worship. I felt the people a bit shocked and wanted to avoid me. I felt that I get pressure and stigma. Hence, I was afraid for going out and shopping. Many people did not put any respect to me when I got infected (Participant 6).

The most difficult thing I faced (when get infected) was $90 \%$ of neighborhoods did not accept me as their neighbor. I felt guilty when other people covering their nose and mouth when they were passing in front of my house. Event more the RT (local chairman of the household) also did not support me (at that time) (participant 9).

Physically, I get traumatic because I have been infected (positive COVID). Hence, I feel uncomfortable if there is a crowd (participant 10).

In fact, what made me stress was the environment (neighborhoods) because they gossiped about me. The neighbors' kids still do not want to play with my kids (participant 11).

\section{Social support}

I got a support from all my friends. My friends did not stay away from me as well as my neighbors. They all accept me as usual (participant 2).

When I did self-quarantine at home, my husband was accompanying me. I got helped from my neighbors 
and my workmates. My neighbors delivered me food every day. I have been controlled by OSCHS (K3). They routinely delivered me vitamins and sometimes food. My friends (also) support me to not being panic and to have a positive feeling (participant 3 ).

Alhamdulillah (Thanks god), I was excited not to hesitate, continue to doing normal activates because my friends did not persecute me (Participant 4).

I was accompanying by my family when I did selfquarantine. One of my family members was negative, so they served me food, vitamins (participant 5).

My neighbors, health-care workers and RT (chairman of neighborhood) supported me (participant 7).

I got lot of sad experience and psychological traumatic because I had a baby at home. When I get infected, my baby just 2 weeks old. Until now, I have not meet up him yet, it is been 1.5 months. That's hard and sad feeling for me. I still contact OSHCS (K3) and hope will negatively very soon (participant 9$)$.

Well, when I got infected, automatically my relationship between my kids and me was in trouble. At that time, I did tawakkal (surrender to god) because my last child still slept with me due to I did not have any choices. I afraid to entrust my child with the neighbors, because I afraid my children being a spreader of COVID-19 too (participant 10).

What made me so stressful was not being able to do outing, gathering with my family, friends. And that was weird (participant 11).

(When get infected) it was like getting into a lion's drum. Because my wife is pregnant, but I have to stay with her (Participant 12).

\section{Stress management}

Without stress management properly, selfmanagement will not be carried out properly also. Stress management in this study more focuses on sharing experiences with fellow COVID-19 sufferers. They told for not to think too much about the COVID-19 infection they experience and keep thinking positively. Sometimes, they are worried about the condition of their family member, especially their children. They are worried that their family members will be infected with COVID-19. They need to ensure that their family conditions are always safe so that they can focus more on recovering. During their isolation, they became closer to their god. They use their moments of self-isolation to reflect on past mistakes they have experienced. They believe that the COVID-19 they get comes from past sins. The theme of stress management is divided into four sub-themes, namely sharing experience each other's, reducing negative emotional, self-introspection, and make sure the family member condition.

\section{Sharing experience each other's}

(When get infected) I shared information each other's to avoid stress. I shared information about how to manage our stress as well as improve internal coping (participant 2).

\section{Reducing negative emotional}

I tried to think positively that I could recover from COVID-19 for my family (participant 3).

Even though we are infected whether with symptoms or not, we have to keep calm, try to happier. The point is not to overthink. If we are getting infected, just accepted it (Participant 5).

To overcome (when being infected), I tried to keep calm. Moreover, if I got breathless, I reduced activities (participant 6).

I advise you not to worry, try to have positive feeling (participant 7).

I play game to get positive feeling (participant 9).

I think we need to have positive way of thinking bro, in the past, we were being afraid by negative content of social media about COVID-19. But now, I try to positive thinking, what should be happen, let it happen (participant 10).

\section{Self-introspection}

I feel this disease (COVID-19) is indeed to fade away our sins. I think this is the way God warns us, to get closer to him (participant 2).

We could do self-reflection, maybe we have been neglecting a health protocol (participant 4).

I felt more intense to do spiritual things. In the past my prayer was not routine, but now is getting better (participant 7).

As long as being infected, my worship was being intensified, I reflected my sins so far (participant 8).

The thing that I did when I get stressed was pray to god, be patient. I believe that, all it happened because of god willing (participant 11).

\section{Make sure the family member condition}

When I did self-isolation, I tried to monitor my family who were contacted with me. Fortunately, my family was negative so I feel calmer and focus to myself (participant 7).

I did video call with my wife, that's made my mind's burden reduced (participant 9 ). 


\section{Focus on learning}

Health professionals with COVID-19 made various efforts to recovery. They are trying to find information that can help them recover immediately. The information they are looking for comes from other health professionals who have recovered from COVID19, YouTube, and google search. therefore, the theme of focus on learning in this study is divided into four subthemes, namely looking for information from survival COVID-19, looking for information from YouTube, and looking for information from google search.

\section{COVID-19}

\section{Looking for information from survival}

I was taught by my friends how to deal with stress and anxiety (survivors COVID-19) (participant 2).

I also consult with my friends who recovered from COVID-19 (participant 3).

\section{Looking for information from YouTube}

I was looking information (about COVID-19) from YouTube channel (participant 2).

\section{Looking for information from Google search}

I knew that I was being recovered because I looked the information from google search. In fact, COVID-19 has left sequalae (participant 6).

I try to update my information from internet and official website (participant 7 ).

\section{Discussion}

Self-management is an important aspect in handling COVID-19 that has been released by the Indonesian government [3]. Self-management is able to increase the chances of recovery or even avoiding COVID-19 infection at the same time [16]

Health professionals have a higher risk of being infected with COVID-19 than other professions because the chances of being exposed to this virus are much greater in a hospital environment [17]. Based on the theory, self-management has a positive impact on the quality of one's health [18], [19], [20]. The fact that has been found so far, poor self-management in self-awareness to prevent the spread of the virus, ignoring healthy living habits, or not digging deeper information about COVID-19 makes the spread of COVID-19 continuously [16], [21]. The experience of health workers in self-management while struggling to recover quickly from COVID-19 needs to be studied to be used as valuable information for Indonesian society in general. In addition, the experience of these health professionals can also be used as a basis for making a policy at the hospital so that the incidence of COVID19 infection for health workers can be prevented. The major themes in this study consist of four themes, namely self-awareness, social relationships, stress management, and focus on learning.

Self-awareness is an understanding of thought and feelings so someone can find out the strengths, weaknesses, drives, and values that occur to him and others. Individuals with good self-awareness can read social situations and understand other people's expectations of them [22]. Self-awareness in controlling and handling COVID-19 is crucial to prevent the spread of COVID-19. Self-awareness shown by health workers who are struggling to recover from COVID-19 infection in this study consists of efforts to prevent transmission [4]. They do this to prevent transmission back to their immediate family and other people who live around their environment. Wear of masks and disinfection of the surrounding area will be useful to prevent transmission of COVID-19 [3], [9]. Improving the immunity system will also be very useful in the recovery process of COVID-19 [23], [24]. Efforts such as sunbathing, dietary adjustment, and consuming vitamins continuously can increase immunity to accelerate the recovery process from COVID-19 infection [7]. All that self-management they do is fully conscious without coercion from others.

COVID-19 makes a person have to limit their social relationships with family or society [25]. Sometimes when they stay away from social activities, they become more reflective and even think about negative things like shunned by their society and death [26]. Social support from family, colleagues, and loved ones is essential during this phase. Social support will make them are not lonely so that they are more enthusiastic to recover from disease [27]. The support needed from the family is a feeling of security and fulfillment of basic needs such as nutrition. Meanwhile, support from colleagues is more on shifting the workload, so that they can more focus on the recovery process.

Stress management is one of the big themes in this study. Stress management has an impact on a person's health [28]. Stress management shown by health workers who are struggling to recover from COVID-19 in this study is more about sharing experiences with fellow COVID-19 sufferers through mobile devices. They also tried to get closer to God and reflect on disease they suffered because of past mistakes they had committed. Getting closer to God makes a person calmer, this serenity will support good immunity so that the COVID-19 recovery process can be faster than usual [29]. Ensuring that the condition of the closest family remains healthy also makes COVID19 survivors can be more focus on recovery [30].

Health workers apparently continue to seek information from various sources so that they can 
quickly recover from COVID-19. The learning resources they accessed during self-isolation were colleagues who had recovered faster from COVID-19. Learning from seeing the success of other people in managing health will inspire someone to get well soon [31]. Other sources they use are YouTube and Google Search [32]. The combination between other experiences, observable media such as reading material and videos will simplify the learning process about health [33]. Providing testimonials from health workers who have recovered from COVID-19 by electronic media like television, web, and YouTube from the trusted sources which providing by the government can help COVID-19 survivors get other learning resources to recover from COVID-19 immediately.

\section{Conclusion}

Health professionals have a higher risk of being infected with COVID-19 than other professions and self-management is an important aspect in handling COVID-19. Self-management among health professional survivors from COVID-19 found in this study consists of four themes, namely self-awareness, social relationships, stress management, and focus on learning. The experience of health workers in selfmanagement while struggling to recover quickly from COVID-19 needs to be studied and used as valuable information for Indonesian society. Thus, the government can maximize the promotion of self-management.

\section{AQ1 References}

1. Syed Khalid M, Aljohani MM, Alomrani NA, Oyoun AA, Alzahrani O, Ahmad MA, et al. COVID-19 and immune function-"A Significant" zinc. Orient J Chem. 2020;36(6):1026-36. https:// doi.org/10.13005/ojc/360604

2. Johns Hopkins University. Coronavirus Resource Center; 2021. Available from: https://www.coronavirus.jhu.edu/map.html.

3. Kementrian Kesehatan. Dashboard Kasus COVID-19 di Indonesia; 2021. Available from: https://www.kemkes.go.id/ article/view/20012900002/Kesiapsiagaan-menghadapi-InfeksiNovel-Coronavirus.html.

4. Yuniti IG, Sasmita N, Komara LL, Purba JH, Pandawani NP. The impact of covid-19 on community life in the province of Bali, Indonesia. Int J Psychosoc Rehabil. 2020;24(10):1918-29.

5. Mahendradhata $Y$, Trisnantoro $L$, Listyadewi $S$, Soewondo $P$, MArthias T, Harimurti P, et al. The Republic of Indonesia Health System Review. Vol. 7. Geneva: World Health Organization; 2017. p. 1.

6. World Health Organization. Health worker exposure risk assessment and management in the context of COVID-19 virus. Guia Provisional. 2020;2(1):1-6.

7. Lauren C, Iskandar A, Argie D, Malelak EB, Suranta SE, Mawardy R, et al. Strategy within limitations during COVID-19 pandemic in Indonesia: Shortage of PPE, prevention, and neurosurgery practice. Bali Med J. 2020;9(3):682-4. https://doi. org/10.15562/bmj.v9i3.1825

8. Pragholapati A. New Normal "Indonesia" After Covid-19 Pandemic. 2020. p. 1-6.

9. Pranata S, Nur FA, Wulandari H, Zainuddin MJ, Hidayat M. New normal at islamic boarding school during the Covid-19 pandemic in Sumbawa Island. Int Conf Soc Sci. 2021;514:201-4. https:// doi.org/10.2991/assehr.k.210101.044

10. Groenewald T. A phenomenological research design illustrated. Int J Qual Methods. 2004;3(1):42-55.

11. Morrow R, Rodriguez A, King N. Colaizzi's descriptive phenomenological method. Psychologist. 2015;28(8):643-4.

12. Colaizzi P. Psychological research as the phenomenologist views it. In: Valle RS, King M, editors. Existential-phenomenological Alternatives for Psychology. New York: Oxford University Press; 1978. p. 48-71.

13. Santhosh Kumar C, Somasundara Yale S. Identifying and eliminating bias in interventional research studies-a quality indicator. Int J Contemp Med Res. 2016;3(6):2454-7379.

14. Polit DF, Beck CT. Essentials of Nursing Research: Appraising Evidence for Nursing Practice. $8^{\text {th }}$ ed. Philadelphia, PA: Lippincott Williams and Wilkins; 2015.

15. Shenton AK. Strategies for ensuring trustworthiness in qualitative research projects. Educ Inf. 2004;22(2):63-75. https://doi.org/10.3233/efi-2004-22201

16. Plevinsky JM, Young MA, Sy PD, Carmody JK, Durkin LK, Gamwell KL, et al. The Impact of COVID-19 on pediatric adherence and self-management. J Pediatr Psychol. 2020;45(9):977-82. https://doi.org/10.1093/jpepsy/jsaa079 PMid:32929482

17. Liao C. Emergency stress management among nurses : Alesson from the COVID-19 outbreak in China-a cross-sectional study. J Clin Nurs. 2021;30(3-4):433-42.

PMid:33141483

18. Pranata S, Wu SV, Alizargar J, Liu J, Liang S, Lu Y. Precision health care elements, definitions and strategies for patients with diabetes: A literature review. 2021;18(12):6535. https://doi. org/10.3390/ijerph18126535

19. Lai PC, Wu SF, Alizargar J, Pranata S, Tsai JM, Hsieh NC Factors influencing self-efficacy and self-management among patients with pre-end-stage renal disease (Pre-esrd). Healthc. 2021;9(3):1-12. https://doi.org/10.3390/healthcare9030266 PMid:33801477

20. Pranata S, Wulandari H. A concept analysis of Self-management among diabetes mellitus. Int J Nurs Health Serv. 2021;4:356-67.

21. Gupta SK, Lakshmi PV, Kaur M, Rastogi A. Role of selfcare in COVID19 pandemic for people living with comorbidities of diabetes and hypertension. J Family Med Prim Care. 2020;9(11):5495-501. https://doi.org/10.4103/jfmpc. jfmpc_1684_20 PMid:33532385

22. Mercado E. Level of awareness, adherence to diet, selfmonitoring and medication regimen among diabetic patients : A basis for improving diabetes specialty clinic services. J Health Med Inf. 2019;10(1):1-7.

23. Fathi F, Sami R, Mozafarpoor S, Hafezi H, Motedayyen $H$, Arefnezhad R, Eskandari N. Immune system changes during COVID-19 recovery play key role in determining disease severity. Int J Immunopathol Pharmacol. 2020;34. https://doi. org/10.1177/2058738420966497 PMid:33076729

24. Chowdhury MA, Hossain N, Kashem MA, Shahid MA, Alam A. Immune response in COVID-19: A review. J Infect Public Health. 2020;13(11):1619-29. https://doi.org/10.1016/j.jiph.2020.07.001 


\section{PMid:32718895}

25. Naser AY, Al-Hadithi HT, Dahmash EZ, Alwafi H, Alwan SS, Abdullah ZA. The effect of the 2019 coronavirus disease outbreak on social relationships: A cross-sectional study in Jordan. Int J Soc Psychiatry. 2020;0020764020966631. https:// doi.org/10.1177/0020764020966631

PMid:33103566

26. Menzies RE, Menzies RG. Death anxiety in the time of COVID-19: Theoretical explanations and clinical implications. Cogn Behav Ther. 2020;13:1-11. https://doi.org/10.1017/ s1754470x20000215

PMid:34191938

27. Xu J, Ou J, Luo S, Wang Z, Chang E, Novak C, et al. Perceived social support protects lonely people against COVID-19 anxiety: A three-wave longitudinal study in China. Front Psychol. 2020;11:566965. https://doi.org/10.3389/fpsyg.2020.566965 PMid:33240152

28. Hagger MS, Keech JJ, Hamilton K. Managing stress during the coronavirus disease 2019 pandemic and beyond: Reappraisal and mindset approaches. Stress Health. 2020;36(3):396-401. https://doi.org/10.1002/smi.2969

Author Queries???

AQ8: $\quad$ Kindly cite reference 14 in the text part

\section{PMid:32588961}

29. Roman NV, Mthembu TG, Hoosen M. Spiritual care-"A deeper immunity"-a response to Covid-19 pandemic. Afr J Prim Health Care Fam Med. 2020;12(1):1-3. https://doi.org/10.4102/phcfm. v12i1.2456

PMid:32634003

30. Sun N, Wei L, Shi S, Jiao D, Song R, Ma Msc L, et al. Qualitative study: Experienced of caregivers during Covid19. Am J Infect Control. 2020;48:592-8. https://doi.org/10.1016/j. ajic.2020.03.018

PMid:32334904

31. Raza SA, Qazi W, Khan KA, Salam J. Social isolation and acceptance of the learning management system (LMS) in the time of COVID-19 pandemic: An expansion of the UTAUT model. J Educ Comput Res. 2020;59(2):183-208. https://doi. org/10.1177/0735633120960421

32. Dhawan S. Online learning: A panacea in the time of COVID-19 crisis. J Educ Technol Syst. 2020;49(1):5-22.

33. Schunk DH. Learning Theory an educational perpective. Nature. 2012;322:399. 